\title{
A BRINCADEIRA DE PAPÉIS NA EDUCAÇÃO INFANTIL: ATIVIDADE OBJETIVADA A PARTIR DA ORGANIZAÇÃO DE ESPAÇOS E DA INSERÇÃO DE NOVOS TEMAS.
}

\author{
EL JUEGO DE ROLES EN LA EDUCACIÓN DE LA NIÑEZ TEMPRANA: UNA \\ ACTIVIDAD ORIENTADA A ORGANIZAR ESPACIOS E INSERTAR NUEVOS \\ TEMAS.
}

\section{THE ROLE OF PAPERS IN CHILDREN EDUCATION: ACTION OBJETIVADE FROM THE ORGANIZATION OF SPACES AND INSERTING NEW TOPICS}

\author{
Gislaine Rossler Rodrigues GOBBO ${ }^{1}$ \\ Lucinéia Aparecida Alves FERREIRA ${ }^{2}$
}

RESUMO: A brincadeira de papéis na perspectiva Histórico-Cultural é uma forma muito evoluída de brincar. Nela a criança reconstitui a atividade social e tenta representá-la, reproduzindo a atividade concreta das pessoas em suas relações e diversidade. Por isso, os temas dos jogos podem ser bem variados e cambiáveis, dependendo das situações objetivas das quais a criança participa. Como atividade dominante da Idade pré-escolar, a brincadeira de papéis pode propiciar o desenvolvimento psíquico infantil. Assim, o objetivo deste estudo é investigar a influência dos espaços organizados e inserção de novos temas nas brincadeiras de papéis sociais. Método: foram selecionadas 25 crianças de quatro a cinco anos participantes da Educação Infantil Municipal da cidade de Bauru- SP. Foi adotada a análise observacional e descritiva. Resultados: Os dados gerados pelos gráficos 1 e 2 e quadros 1, 2, 3 demonstram, sobretudo, que o tema e o argumento da brincadeira possibilitaram um avanço nos níveis de desenvolvimento da brincadeira de papéis depois do estudo do tema e desempenho dos papéis nos espaços.

PALAVRAS-CHAVE: Educação infantil. Brincadeira de papéis sociais. Espaços escolares. Temas e conteúdos da brincadeira de papéis sociais.

RESUMEN: El juego de roles en la perspectiva histórico-cultural es una forma muy evolucionada de jugar. En ella, el niño reconstituye la actividad social e intenta representarla, replicing la actividad concreta de las personas en sus relaciones y diversidad. Por tanto, los temas de los juegos pueden ser muy variados e intercambiables, dependiendo de las situaciones objetivas de las que participe el niño. Como actividad dominante de la edad preescolar, el juego de roles puede proporcionar el desarrollo psíquico del niño. Así, el objetivo de este estudio es investigar la influencia de los espacios organizados y la inserción

${ }^{1}$ Faculdade Anhanguera de Bauru, Bauru - SP - Brasil. Docente. Graduação Letras e em pedagogia. Pósgraduação latu sensu em Artes e em Educação Infantil. Mestrado e Doutorado Unesp Marília, linha de pesquisa práticas pedagógicas. Diretora de Escola de Educação Infantil e Coordenadora de área de Educação Infantil do município de Bauru. ORCID: <https://orcid.org/0000-0001-9904-2128>. E-mail: gislainerrgobbo@gmail.com

${ }^{2}$ Prefeitura Municipal de Bauru (PMB), Bauru - SP - Brasil. Professora de Educação Infantil do Município de Bauru. Participante na formação docente do N.A.P.E.M - Núcleo de Aperfeiçoamento Profissional da Educação Municipal. Pós-graduação latu sensu em psicopedagogia Institucional. Participante do PNAIC. E-mail: Lucineia.caio@ hotmail.com 
de nuevos temas en el juego de roles sociales. Método: seleccionamos a 25 niños de cuatro a cinco años de edad que participaron en la educación de los niños municipales en la ciudad de Bauru-SP. se adoptó un análisis observacional y descriptivo. Resultados: los datos generados por los gráficos 1 y 2 y los cuadros 1, 2, 3 demuestran, sobre todo, que el tema y el argumento de la obra permitieron un avance en los niveles de desarrollo del juego de roles después del estudio del tema y el desempeño de roles en Espacios.

PALABRAS CLAVE: Educación infantil temprana. Juego de rol social. Espacios escolares. Temas y contenidos del juego de roles sociales.

ABSTRACT: The role play in the Cultural Historical perspective is a highly evolved form of play. In it the child reconstitutes social activity and tries to represent it, reproducing the concrete activity of people in their relationships and diversity. Therefore, the themes of the games can be varied and changeable depending on the objective situations in which the child participates. As a dominant activity of the preschool age, role play can foster children's psychic development. Thus, the objective of this study is to investigate the influence of organized spaces and the insertion of new themes in social role play. Method: 25 children from four to five years of age participated in the Municipal Infantile Education of the city of Bauru- SP. The observational and descriptive analysis was adopted. Results: The data generated by graphs 1 and 2 and tables 1, 2, 3 demonstrate, above all, that the theme and the argument of the play enabled an advance in the levels of development of role play after the study of the theme and performance of roles in Spaces.

KEYWORDS: Child education. Social role play. School spaces. Themes and contents of the social role play.

\section{Fundamentos teóricos}

Conforme a perspectiva da Teoria Histórico-Cultural, a brincadeira- uma atividade inerentemente humana- no período da infância desempenha um papel fundamental no processo de desenvolvimento psíquico humano. A brincadeira não é instintiva, mas uma ação objetiva na qual a criança precisa agir para apropriar-se do mundo que a cerca (ROSSLER, 2006).

Diante do papel da brincadeira de papéis no desenvolvimento infantil e dos fundamentos desta atividade, deve-se atentar para as necessidades e as especificidades desta ação, surgindo a escola como espaço privilegiado para que as crianças vivenciem essa situação. "Buscar a compreensão da importância da brincadeira na vida das crianças é considerá-las como sujeitos concretos, participantes da sociedade em que vivem, e, portanto, tendo direito à brincadeira como uma importante atividade na infância" (ARAÚJO, 2008, p. 27). 
A apropriação dos produtos materiais e simbólicos da atividade dos homens faz parte dos processos de humanização acumulados de forma objetiva ao longo da história. Durante a apropriação dos objetos historicamente criados, é possível subjetivar, ou seja, tornar seu, aquilo que foi criado por outros homens. No caso da criança, tal apropriação dar-se-á por meio das atividades lúdicas. Nesta hipótese, a brincadeira de papéis é um meio pelo qual a criança apreende elementos que constituem o mundo objetivado (ROSSLER, 2006). Pela brincadeira a criança age no mundo como o adulto, assim o imita e, diante da dificuldade de atuação, entra em relação não só com os objetos que estão ao seu alcance, mas também com um mundo mais vasto, que é o das pessoas mais experientes. Dessa forma, aparece uma contradição na brincadeira de papéis: impossibilitada de manusear objetos do mundo do adulto e de agir como ele, a criança brinca, atuando como se fosse um adulto, por meio da brincadeira (LEONTIEV, 2006).

Como atividade dominante na idade pré-escolar, a brincadeira de papéis sociais é a atividade que promove saltos qualitativos no desenvolvimento psíquico infantil. A criança brinca orientando-se por motivos e tendências irrealizáveis. Em decorrência dessa situação, a brincadeira surge da necessidade dos desejos não realizáveis, e por meio dela se generalizam reações afetivas, isto é, a criança imita o comportamento do adulto. Nessa ação, são oportunizadas as vias de substituição de como agir no mundo por uma situação imaginada (GOBBO, 2018).

Durante a brincadeira de papéis, pela atividade lúdica, a criança engendra conteúdos do universo histórico-cultural humano, sendo a relação da criança com a realidade alterada à medida que ela muda a percepção do objeto e o ressignifica. Partindo desta ideia, a força determinadora assumida pelo objeto no mundo real é alterada pela brincadeira em uma situação imaginária, em virtude de que antes a conduta infantil era guiada por sua percepção imediata, e agora, na brincadeira, a criança age perante o significado da situação e, ao transformar o significado dos objetos, subverte as regras impostas pelo real, alterando seu significado. Assim, uma escova de cabelo, um lápis, uma colher ou uma caixa podem ser substitutos do objeto real durante a situação lúdica. Quando a criança subverte a ordem das coisas, fazendo com que o campo de significado se imponha sobre o campo real, está recriando sua realidade e age não só a partir daquilo que vê, mas sua atuação é orientada a partir dos significados que atribui aos objetos. Nos estudos de Vigotski (2008), o significado do brinquedo torna-se o ponto central e os objetos são deslocados de uma posição de domínio para uma posição de subordinação. Por isso, entende-se que a natureza da brincadeira traz a 
transição entre as restrições da vida infantil em relação ao mundo do adulto, as quais podem ser vencidas nos momentos de brincadeira.

Em suma, como atividade principal ou dominante das crianças (dos três aos seis anos), a brincadeira de papéis sociais é o meio pelo qual a criança se apropria do mundo, sendo a atividade que mais afeta o psiquismo da criança nesse período. Desse modo, atua como situação fundamental no processo de humanização, proporcionando às crianças formatos diferentes de relacionamento com a cultura, constituindo-se como maneiras de apropriação da realidade (GOBBO, 2018).

A base representativa, na brincadeira de papéis sociais, é, portanto, a relação entre os próprios homens, isto é, a interação que o homem mantém na vida em sociedade. A reconstrução das relações sociais durante as brincadeiras surge mediante o papel de adulto assumido pela criança, pondo em relação o papel (tema) e as ações (conteúdo) do jogo (ELKONIN, 2009).

O surgimento da brincadeira de papéis sociais está ligado às condições sociais concretas da vida da criança. Para Elkonin (2009, p. 283), "uma das premissas para que a criança adote a representação do papel de qualquer adulto é que capte os trabalhos típicos da atividade desenvolvida por esse adulto", ou seja, para a criança exercer papéis sociais, precisará captar os traços típicos da atividade desenvolvida pelas pessoas na sociedade.

Diante do exposto, pode-se presumir que a brincadeira de papéis sociais é uma forma muito evoluída de brincar, na qual a criança reconstitui a atividade social e tenta representá-la, reproduzindo a atividade concreta das pessoas em suas relações. Os temas podem ser bem variados e cambiáveis, havendo menção à diferentes épocas da história, condições sóciohistóricas, geográficas e domésticas. Inclusive a criança adota temas das condições concretas de sua vida (ELKONIN, 2009).

Vale destacar que há distinção entre tema e conteúdo. "O tema do jogo é o campo da realidade reconstituída pelas crianças. Como já apontamos, os temas dos jogos são extremamente variados e refletem as condições concretas da vida da criança." (ELKONIN 2009, p. 35). Isso implica que, conforme o meio se enriquece com motivos variados, ampliam-se, também os temas. Por outro lado, o conteúdo das brincadeiras de papéis sociais "é o aspecto característico central, reconstituído pela criança a partir da atividade dos adultos e das relações que estabelecem em sua vida social e de trabalho." (ELKONIN, 2009, p. 35).

\section{Metodologia}


As ações metodológicas foram planejadas em uma Unidade de Educação Infantil Pública Municipal, na cidade de Bauru, Estado de São Paulo. Foram selecionadas 25 crianças participantes da turma do Infantil IV- V, de ambos os gêneros (12 meninos e 13 meninas) entre 4 e 5 anos. Foram pesquisadoras participantes: uma professora de Educação Infantil da Turma Lu. Al.; uma Coordenadora de área da Secretaria Municipal de Bauru G. G. Todos os envolvidos na pesquisa são nomeados com iniciais, escolha motivada para a preservação dos sujeitos.

A geração de dados ocorreu entre os meses de junho de 2017 e junho de 2018, quando eram destinadas até 2 horas semanais para a brincadeira de papéis, dependendo da organização da unidade escolar. Os pais e/ou responsáveis autorizaram a participação do (a) menor no estudo, mediante a assinatura do termo de Consentimento Livre Esclarecido (TCLE) oferecido pela escola. O delineamento do estudo foi observacional e descritivo. Para a geração de dados deu-se ênfase a três situações: $1^{a}$ Ação- Salão de Beleza; $2^{a}$ Ação- Clínica Veterinária e Pet Shop e $3^{a}$ Ação- Hospital.

Como instrumentos de análise, apresentam-se dois gráficos e três quadros de valores qualitativos- descritivos com quatro indicadores de análise: (1) Situação imaginária que conduz às regras e desempenho de papéis (VIGOTSKI, 2008); (ELKONIN, 2009); (2) Temas adotados na brincadeira (ELKONIN, 2009); (3) Construções linguísticas inusitadas, (4) Alargamento dos horizontes cognitivos da criança (MARCOLINO, 2013). A seguir explicitam-se os resultados das três ações e as discussões dos dados.

\section{Resultado e discussão}

Na sequência são elencados os indicadores adotados para a análise: (1) a situação imaginária que conduz às regras e desempenho de papéis (VIGOTSKI, 2008); (ELKONIN, 2009); (2) temas adotados na brincadeira (ELKONIN, 2009); (3) construções linguísticas inusitadas (GOBBO, 2018), (4) alargamento dos horizontes cognitivos da criança (MARCOLINO, 2013). A referência bibliográfica usada no presente trabalho justifica a terminologia adotada para esses indicadores. Ressalta-se que há presença de mais de um indicador em cada situação, porém a análise se ateve àqueles que mais se destacam. Os espaços foram organizados após o estudo dos papéis exercidos pelas pessoas mais próximas das vivências infantis que atuavam em pet shops, hospitais e salão de beleza. A professora e pesquisadora Lu. Al. observou a adoção, pelas crianças, dos temas da brincadeira de papéis sociais referentes às três situações: $1^{a}$ Ação-Salão de Beleza; $2^{a}$ Ação- Clínica Veterinária e 
Pet Shop e $3^{a}$ Ação- Hospital em outros momentos sem a intervenção dos objetos nos espaços, ou seja, após a compreensão dos papéis, a criança realizava uma correspondência com a lógica das relações autênticas e sentidos aprendidos sobre as funções sociais mostradas pela docente.

Elkonin (2009) explica que é possível reconhecer na brincadeira de papéis sociais quatro níveis distintos. O primeiro tem como principal característica as ações propriamente ditas, como brincar de mamãe e filhinha, cujo foco é dar a comida ao bebê e não exercer o papel de mãe. O segundo possui como elemento principal a ação com objeto, em que a lógica da ação é a sucessão observada na vida real. Exemplo disso é a ação de dar de comer ao bebê e a relação com o ato de cozinhar, preparo da comida e organização do espaço do alimento. $\mathrm{O}$ terceiro revela os papéis bem destacados e determinados pela criança já no início da ação de brincar. Nesse nível, a ação de dar comida, agrega-se à de colocar para dormir, tomar banho, etc. "Destaca-se a regra de conduta a que as crianças submetem suas ações." (ELKONIN, 2009, p. 298). O quarto nível focaliza a execução de ações relacionadas às atitudes de outras pessoas, cujos papéis são exercidos pelas pessoas da sociedade. Por exemplo, a professora visita um supermercado e as crianças conversam com as pessoas que trabalham, observam papéis e depois os desempenham, imitando-os. Na situação lúdica, conforme a criança estabelece diferenciações de sentido, ela assume os papéis em um dos quatro níveis (GOBBO, 2018). Tais apontamentos são expostos nos resultados e discussão.

Gráfico 1 - níveis da brincadeira de papéis antes das ações planejadas pela professora.

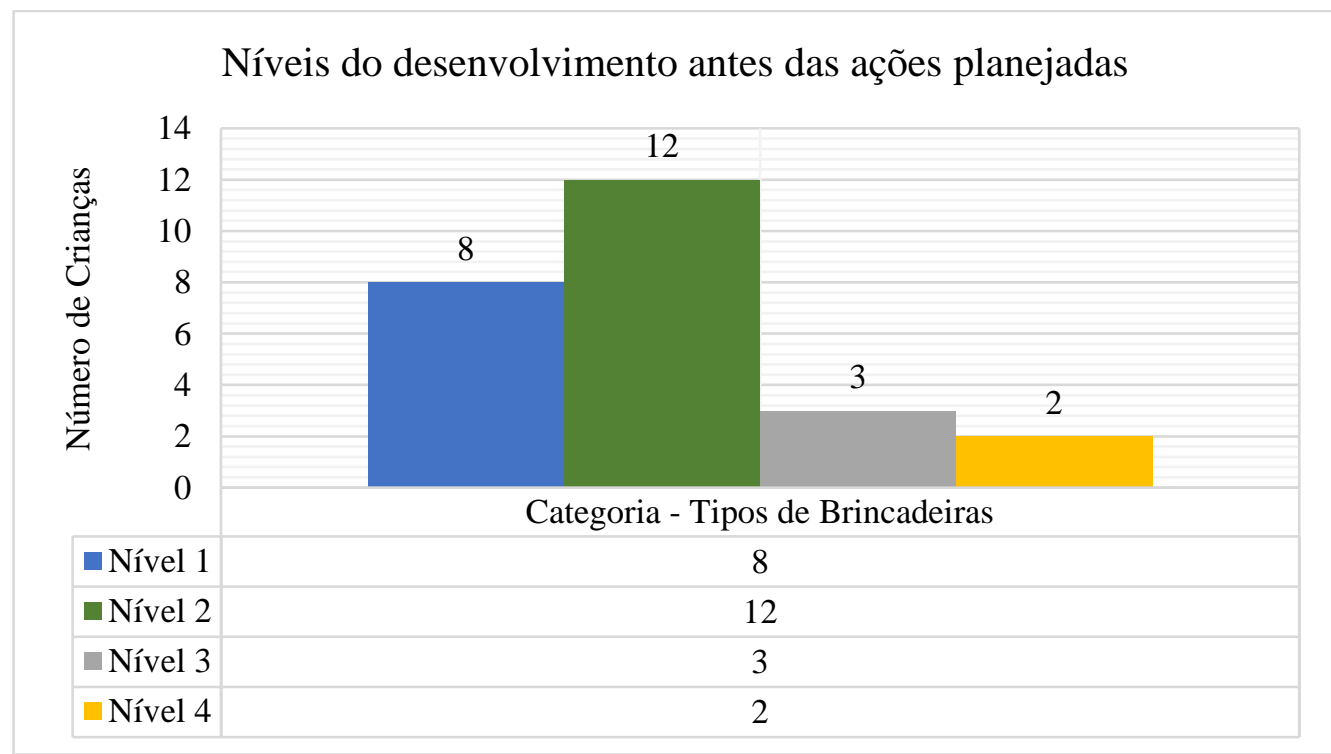

Fonte: Dados da pesquisa (2018) 
Gráfico 2 - níveis da brincadeira de papéis depois das ações planejadas pela professora.

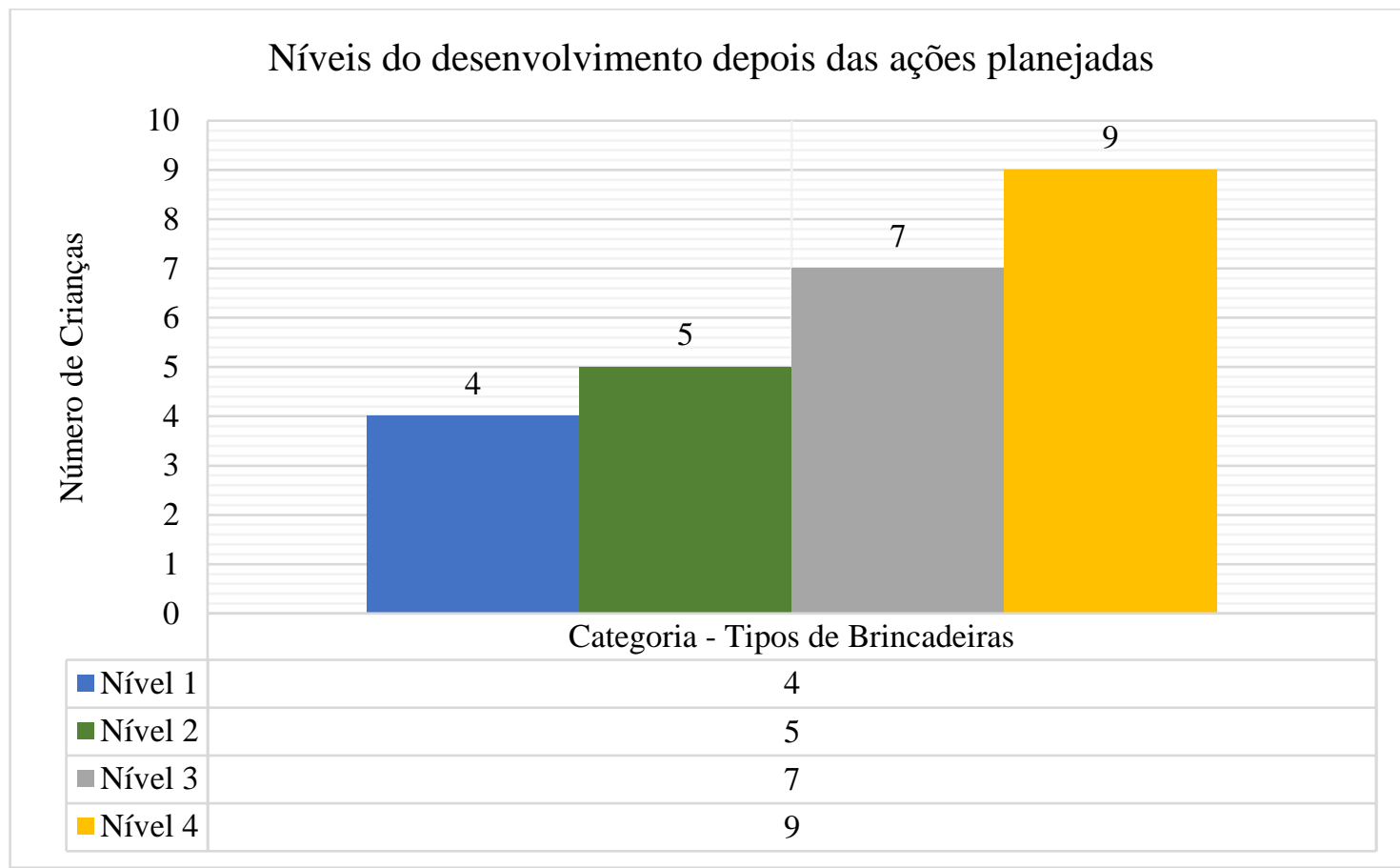

Fonte: Dados da pesquisa (2018)

A análise dos dados nos gráficos 1 e 2 demonstra, sobretudo, que o tema e o argumento da brincadeira possibilitaram um avanço nos níveis de desenvolvimento da brincadeira de papéis depois do estudo e desempenho dos papéis nos espaços. Isto significa que antes da inserção de novos temas e organização de espaços as crianças em sua maioria (vinte crianças) situavam-se nos primeiros níveis, ou seja, oito crianças atuavam no primeiro nível, cujo conteúdo central da brincadeira constitui-se pelas ações com os objetos, o mais importante na representação dos papéis é agir. Tal ação é monótona e constitui-se de uma série repetitiva de movimentos. Estavam no segundo nível de desenvolvimento da brincadeira doze sujeitos participantes, aquele nível que traz a relação da ação com o objeto determinada pela sucessão da vida e observada na realidade. Porém, após a concretização dos estudos e participação nas brincadeiras as crianças tiveram uma evolução, ou seja, no primeiro nível diminuiu para quatro e no segundo nível para cinco. Anteriormente apenas três crianças atuavam no terceiro nível e no quarto somente duas. Entretanto, após a intervenção, houve expansão. No terceiro nível, aquele no qual há menção do papel antes da situação e determina a conduta da criança destacando a regra, houve aumento de três para sete sujeitos, e no nível quatro, no qual há execução de ações relacionando-se a atitude de outras pessoas, cuja fala tem caráter teatral e é manifestada pelo papel nos eventos sociais, estendeu-se de duas para nove crianças. 
Encaminha-se a análise dos indicadores, orientando-a pela organização de espaços e inserção de novos temas na brincadeira de salão de beleza.

Quadro 1- Brincadeira de papéis sociais - Salão de beleza

\section{Tema: Salão de Beleza Bella Lu \\ Data: março a abril}

Participantes: vinte e cinco crianças

\section{Indicadores de análise:}

(1) Situação imaginária que conduz às regras e desempenho de papéis sociais (VIGOTSKI, 2008); (ELKONIN, 2009);

(2) Temas adotados na brincadeira (ELKONIN, 2009);

(3) Construções linguísticas inusitadas,

(4) Alargamento dos horizontes cognitivos da criança (MARCOLINO, 2013)

Falas das crianças: “- Nossa, hoje o salão tá lotado, pega uma revista pra senhora ir olhando!!’( C. Gio.) “- Que cor de esmalte você quer passar moça?”( C. Jo. Ar.) “que chato salão é coisa de mulherzinha". (C.Ya) "põe a mão de molho para fazer as unhas" (C. Ca) “ pinta, pinta... a unha."

\section{Espaços organizados para a ação:}
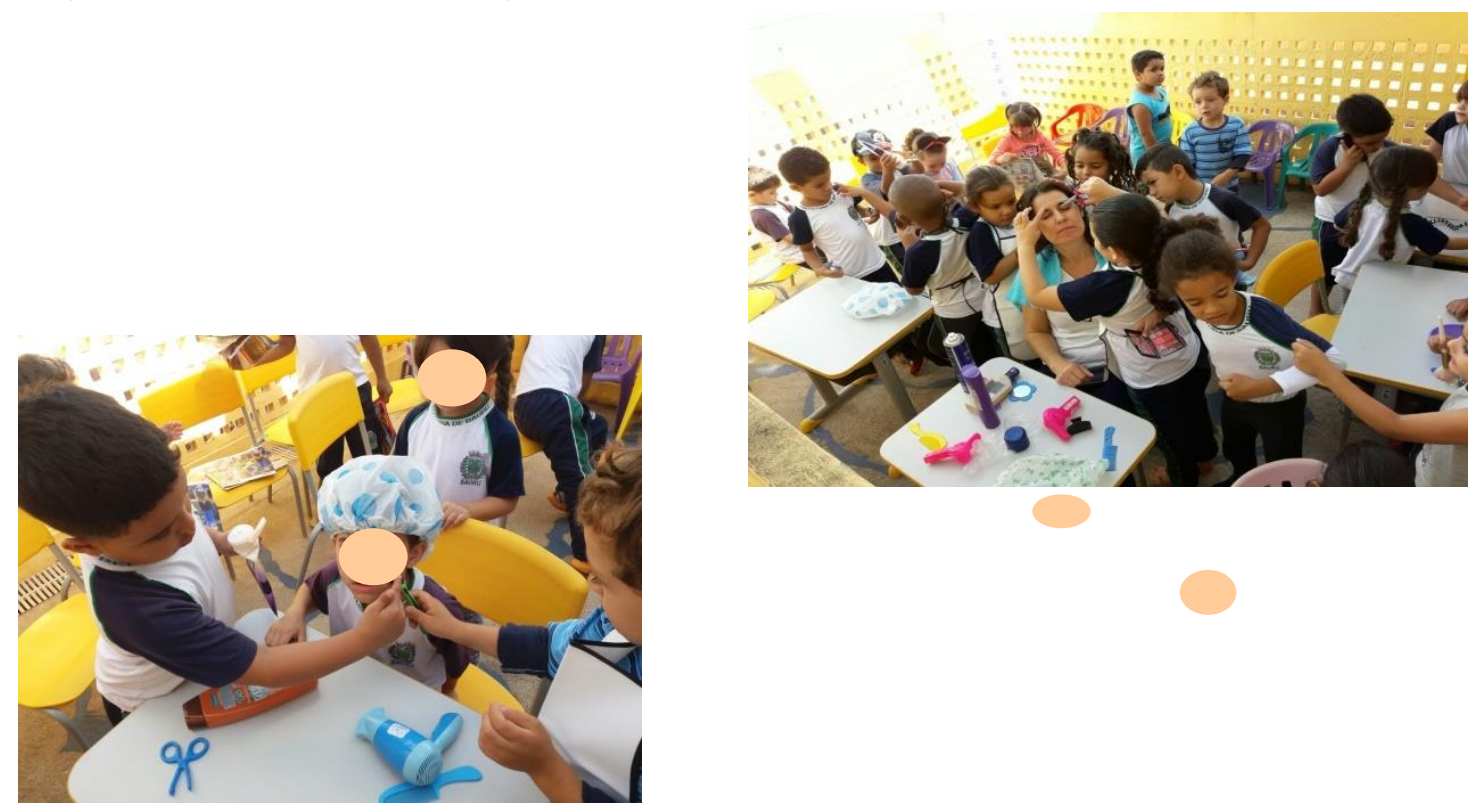

Fonte: Dados da pesquisa (2018) 
Na brincadeira de papéis sociais do Salão de beleza, no primeiro indicador- a situação imaginária que conduz às regras e desempenho de papéis- a criança age contra o impulso imediato. Ao submeter-se às regras do papel durante a brincadeira, ela é impulsionada a atuar contra o que deseja naquele momento. Ao fazer isso, demonstra maior autocontrole, pois "normalmente, a criança vivencia a submissão à regra na recusa daquilo que quer fazer, mas, nesse caso, a submissão à regra e a recusa de agir por impulso imediato é o caminho para a satisfação máxima." (VIGOTSKI, 2008, p. 33).

No segundo indicador, os temas adotados na brincadeira em sua essência proporcionam uma nova relação entre o campo semântico- a situação imaginária- e a situação real. Na $1^{\mathrm{a}}$ ação, na atuação "salão de beleza", os papéis sociais eram manicure, cabeleireiro de corte masculino, barba e bigode, cabeleireira de corte feminino, maquiadora, profissional da hidratação, sala de espera com recepcionista. Como explica Elkonin (2009), a estrutura dos jogos sofre mudanças nos grupos de maior idade, passando da adoção de temas isolados para o argumento desenvolvido metodicamente e do meio imediato para acontecimento da vida social. Os dois fatores foram proporcionados pelas pesquisadoras ao inserirem novos assuntos para a atividade, o que resultou em mudança do caráter da brincadeira, que nos primeiros anos do pré-escolar sofre o impacto dos brinquedos e nos últimos anos é impactada pelas ideias. Além disso, o papel assumido pelas crianças, que no início era sintético e depois adquiriu muitos traços individuais, já que para "as crianças mais velhas não interessa simplesmente este ou aquele papel, mas também a perfeição com que está representando e aumenta a exigência de interpretá-lo com veracidade e força de convicção" (ELKONIN, 2009, p. 236). Registre-se que duas crianças Hy. e Jo. Ar., ao representarem os papéis, evidenciam a autenticidade da brincadeira quando relatam que não havia necessidade de secar o cabelo de C. Lu, pois seu cabelo já estava raspado.

No terceiro indicador as construções linguísticas inusitadas foram identificadas em situações diversas, entre as quais destaca-se o momento em que a professora pesquisadora comentou que haveria a brincadeira de papéis de salão de beleza, e C. Jo. Ar com desapontamento, diz "Que chato! salão é coisa de mulherzinha". Nesse ponto, a pesquisadora realiza uma intervenção, expondo que homens também frequentam o salão para cortar o cabelo e fazer a barba. Dessa forma, a criança motiva-se e participa da ação lúdica.

No quarto indicador- o alargamento dos horizontes cognitivos da criança- houve percepção de que a conduta na submissão dos papéis foi alterada, já que as crianças começaram a aceitar a mudança do papel representando e solicitando a troca de atuação entre os pares. Percebeu-se também a evolução da atenção e da memória, pois as crianças 
descreviam detalhes dos papéis assumidos, como a C. Ya "põe a mão de molho para fazer as unhas" e C. Ca diz "pinta, pinta... a unha." C. Ya mostra maior experiência do papel assumido junto com C. Gio, que, além de molhar as unhas, tem lixa e hidratante para as mãos. Nessa situação, C. Ca apropria-se de outras formas além das que conhecia sobre o papel, internalizando e objetivando outros conhecimentos, pois em outro momento C. Ca imita a conduta dos pares mais experientes e altera sua forma inicial de brincar.

Outro dado relevante, no indicador- alargamento dos horizontes cognitivos da criança, é quando a recepcionista C. Gabi anota em um papel a chegada da cliente C. An usando como recurso mnemônico a escrita como meio de recordar, fazendo alguns signos $\$ \$ \$ \$$ e o número 5 , apontando que havia cinco pessoas em sua frente e que a cliente deveria pegar uma revista e aguardar na sala de espera.

Ao término desta análise, dá-se ênfase à ideia de que, depois da concretização da ação nos espaços organizados pela professora, observou-se que o tema da brincadeira "salão de beleza" esteve presente na escolha e atuação infantil em outros momentos livres, ou seja, sem a organização do espaço planejado para a ação, pois o argumento do jogo adquiriu afinidade para as crianças ao captarem os traços típicos da atividade desempenhada pelos adultos.

Apresenta-se a segunda situação da brincadeira de papéis sociais: Clínica Veterinária e Pet Shop.

Quadro 2 - Brincadeira de papéis sociais - Clínica Veterinária e Pet Shop Tema: Clínica Veterinária e Pet Shop

Nomeado- patrulha canina

Data: abril e maio

Participantes: vinte cinco- 25

\section{Indicadores de análise:}

(1) Situação imaginária que conduz às regras com desempenho de papéis (VIGOTSKI, 2008); (ELKONIN, 2009);

(2) Temas adotados na brincadeira de papéis sociais (ELKONIN, 2009);

(3) Construções linguísticas inusitadas,

(4) Alargamento dos horizontes cognitivos da criança (MARCOLINO, 2013)

\section{Falas das crianças:}

( Jo. Ar.)"- Meu cachorrinho Max vai castrar, ele não quer ser papai, não quer ter filhote, ele tá latindo muito.” ( Dav.) “- Meu cachorro tá engasgado com osso, será que ele vai morrer?" 
( An.) “-Moço, eu preciso de ração pra galinha, só tô vendo ração de gatos ué!!?

(Lo. Be.)" -Vendedora, eu quero comprar uma caixa de remédio de verme.”(Da. Au.)"-

\section{Espaços organizados para a ação:}
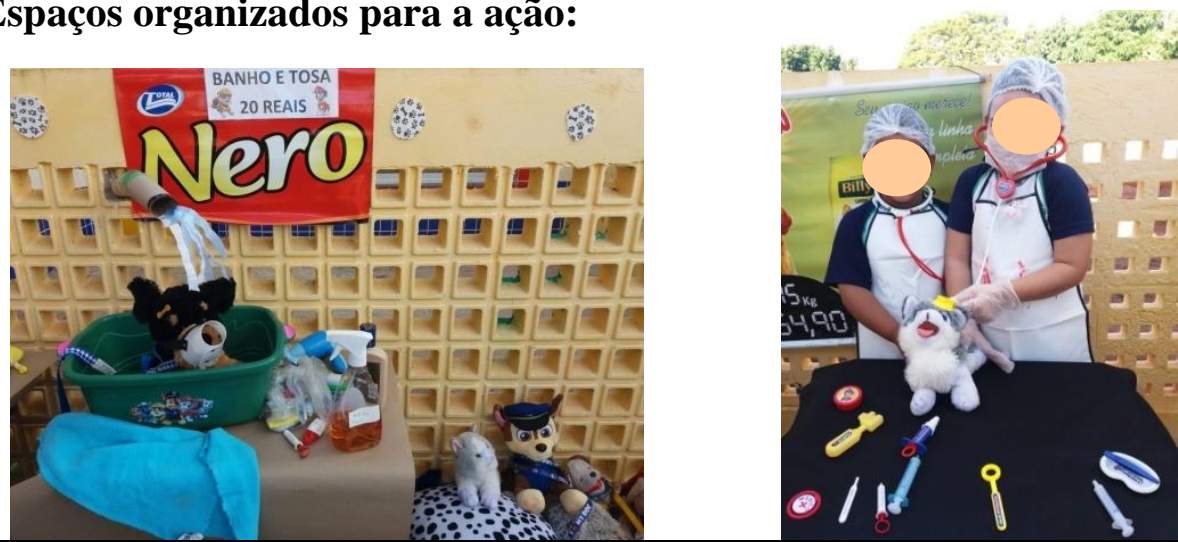

Fonte: Dados da pesquisa (2018)

No primeiro indicador- a situação imaginária que conduz às regras e desempenho de papéis (VIGOTSKI, 2008); (ELKONIN, 2009): a professora e pesquisadora Lu. Al. explicou para as crianças os papéis sociais assumidos pelos adultos em uma Clínica Veterinária e Pet Shop. A situação imaginária em si já contém regras de conduta, apesar de a brincadeira em si não exigir regras especificamente declaradas, ou seja, papéis e ações formulados com antecedência. A criança imagina-se no papel do profissional ou pessoa responsável pelo animal e comporta-se de acordo com as regras do comportamento humano, mas cria ações e falas submetidas aos papéis desempenhados. Assim, Conforme Vigotski (2008, p. 28) "Qualquer brincadeira com situação imaginária é, ao mesmo tempo, brincadeira com regras e qualquer brincadeira com regras é brincadeira com situação imaginária." Isto acontece na medida em que a situação imaginária contém regras, pois embora a criança seja livre no momento que brinca, sua liberdade é ilusória, pois subordina-se às regras do papel assumido. Por isso a brincadeira no espaço do Pet estava submetida às condutas dos papéis, nas quais as crianças desempenham o brincar, como dito por C. Jo Ar.: "Meu cachorrinho Max vai castrar, ele não quer ser papai, não quer ter filhote, ele tá latindo muito.” A criança atua de acordo com a situação, existindo uma situação imaginária concomitante às regras decorrentes do papel assumido.

Os materiais utilizados foram providenciados pela professora e pesquisadora: cartazes para identificação dos espaços do pet shop (caixa, recepção, banho e tosa, medicação, ração, coleiras, brinquedos, veterinário); confecção de monitor com gaveta contendo dinheiro de brinquedo; embalagens vazias de medicações; miniaturas de brinquedos para pet; animais de pelúcia; bacias plásticas para o banho e utensílios como escova, secador, toalha; folders 
emprestados de pet shops, gaiolas para transporte de animais, maleta de veterinário e amostras grátis de rações.

No indicador os temas da brincadeira na clínica veterinária e pet shop estavam presentes as funções de: recepcionista, caixa, veterinários, profissional do banho e tosa, clientes, balconista da farmácia e da loja de ração, vendedor de acessórios para animais e representante comercial de ração. Tais papéis representados pelas crianças, em decorrência dos estudos proporcionados pela pesquisadora, demarcam o que Elkonin (2009) defende sobre o desenvolvimento do tema, indo da execução das ações lúdicas (representação das ações: lavar, cozinhar) aos modelos de papéis (produção de imagens). Nestes últimos, há encenação da criança dirigida pelo brinquedo e dependente da afinidade e das experiências infantis com o tema. Na situação descrita, as crianças se apropriaram dos papéis trazidos pelas pesquisadoras e com desenvoltura representaram eventos sociais do espaço pet shop.

No indicador construções linguísticas inusitadas especificamente na fala, $\boldsymbol{C}$. Gabi diz "professora você esqueceu de me dar a calculadora para fazer a conta, o cliente comprou ração e remédio". A situação explicita que a presença da calculadora afetou a forma de a criança conduzir sua ação no cotidiano da escola. O objeto solicitado pela criança contribuiu para que os envolvidos no momento da brincadeira imaginassem uma nova cena enquanto brincavam. No processo de atuação na brincadeira do pet shop a $\boldsymbol{C}$. Ro trouxe de casa acessórios, tais como laços, brilhos, spray perfumado e focinheira, pois a mãe é funcionária de um pet. Nessa ação houve a reelaboração da função ou papel, observa-se que as crianças repensaram um novo contexto para a brincadeira, surgindo novas palavras que se tornaram generalizadas. Todas as frases verbalizadas apontam para alguns fatores que promovem a imaginação. Além da reelaboração, há a modificação dos significados do objeto, recriação de novos signos e separação do campo conceitual desencadeado por objeto pivô. Tudo isso assinala que os temas enriquecem e alteram o conteúdo da brincadeira, que antes era referente ao cotidiano.

Por fim, no indicador de análise: alargamento dos horizontes cognitivos da criança, é possível apontar algumas situações no sentido e na ação quando ocorre a separação do significado da palavra, pois no momento em que os rolos de papéis são usados como chuveiros do pet, ou seja, o objeto, transforma-se num ponto de apoio (pivô) para a separação do significado, assim a criança separa o significado do objeto real (rolo de papel), ao encontrar um pivô em outro objeto, ou seja, uma característica que contribua com a substituição do objeto real. Nesse momento crítico, modificam-se radicalmente as estruturas 
psicológicas que determinam a relação da criança com a realidade, substituindo objeto real por outro imaginado por ela (VIGOTSKI, 2008).

Em síntese, observou-se a presença do tema clínica veterinária e pet shop em outros momentos da brincadeira de papéis sociais, na atuação livre e autônoma da criança sem a organização do espaço e presença dos objetos específicos, isto se explica pela brincadeira em suas formas mais evoluídas não depender do objeto, nem de seu uso, mas das relações que as pessoas estabelecem com tais objetos.

Dando continuidade, apresenta-se a terceira situação da brincadeira de papéis sociais: o hospital.

Quadro 3 - Brincadeira de papéis sociais - Hospital

\section{Tema: Hospital Med Lu}

\section{Data: maio a junho}

Participantes: vinte cinco crianças- 7 crianças com quatro e 18 com cinco anos

\section{Indicadores de análise:}

(1) Situação imaginária que conduz às regras e desempenho de papéis (VIGOTSKI, 2008); (ELKONIN, 2009);

(2) Temas adotados na brincadeira (ELKONIN, 2009);

(3) Construções linguísticas inusitadas,

(4) Alargamento dos horizontes cognitivos da criança

(MARCOLINO, 2013)

Falas das crianças: Nossa, num aguento esperar aqui na sala de espera, credo que demora pra me chamar!!”(Hy) “- A senhora precisa pegar a senha pra ser atendida.”(Ya) “- A injeção não vai doer viu moço, não precisa chorar!” ( Lu.) “ - O SAMU vem voando com gente doente, escuta o barulho!'(Ga.)

C. Ya "fala C. Rafa, não se esqueça de pedir o cartão do SUS para o paciente, e você C. Hy precisa falar no rádio e não ficar parado, assim, como você está".

C Jo. Ar "reclama de dor paciente você está muito quieto." (C. Manu)"não quero tirar sangue, tenho medo",

\section{Espaços organizados para a ação:}
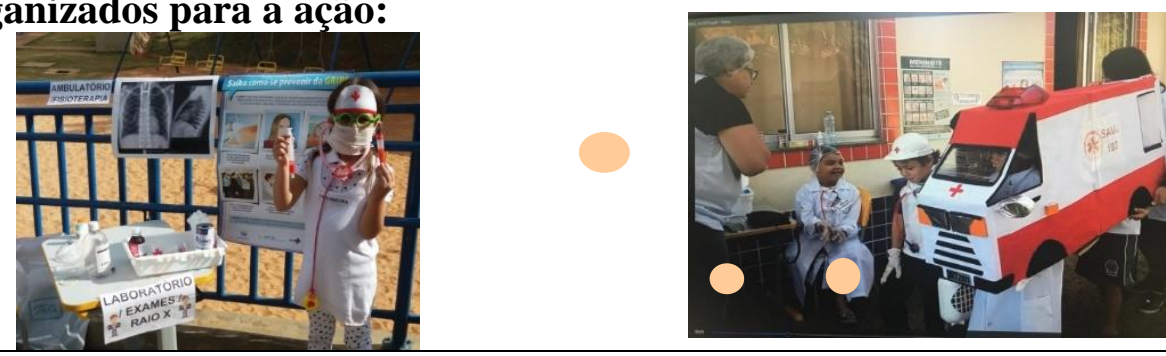

Fonte: Dados da pesquisa (2018)

Temas em Educ. e Saúde, Araraquara, v. 14, n. 2, p. 268-283, jul./dez., 2018 
No indicador a situação imaginária que conduz às regras e desempenho de papéis, a organização do espaço foi pensada para definir cada papel assumido pela criança. Em situações de rodas da conversa a professora e pesquisadora Lu. Al. procurou ouvir as crianças a respeito do conhecimento prévio dos papéis desempenhados no espaço e, a partir do levantamento da zona de desenvolvimento real da criança, conduziu o tema trazendo imagens em vídeos dos espaços de pronto-atendimentos e áudio e vídeo de pessoas exercendo seus papéis. Foram também divulgadas gravuras para possibilitar a compreensão da criança sobre a função. Na voz de C. Ya "fala C. Rafa, não se esqueça de pedir o cartão do SUS para o paciente, e você, C. Hy precisa falar no rádio e não ficar parado, assim, como você está” e C Jo. Ar "reclama de dor paciente, você está muito quieto." As crianças expressam as condutas previstas para cada papel representado. A recepcionista C. Ya explica como o outro recepcionista deve atuar e a criança C. Jo Ar, na função de médico, deseja que o paciente reclame de dor.

No segundo indicador, os temas adotados na brincadeira surgiram a partir da inserção dos seguintes espaços: recepção do hospital, portaria, sala de espera, triagem, sala de sutura, emergência, laboratório de raio x, coleta de sangue, consultório médico, internação, farmácia e a confecção de uma viatura feita com materiais recicláveis. Conforme dito, houve parceria com os pais, que enviavam, na data previamente comunicada por bilhete, objetos, roupas, cartazes e acessórios para compor a atividade. Os materiais selecionados para o desempenho de cada função foram confeccionados: a viatura do SAMU, o rádio amador do porteiro, as senhas para os pacientes, o cartão do SUS. Foram também usados aparelhos de telefones fixos, teclados de computadores, materiais de uso hospitalar: luvas, toucas, máscaras, ataduras, gaze, esparadrapo, tesoura sem ponta e sem corte, algodão, estetoscópio de brincadeira, termômetros, aferidor de medir pressão, aparelho de inalação, embalagens de remédios, pomadas cadeira de roda e maletas de kit de primeiros socorros. Todos esses objetos eram inativos. Houve também a elaboração de um receituário médico simbólico. A temática foi fotografada, filmada e registrada, também, em desenho, escrita e gráficos. Conforme Elkonin (2009, p. 262) "nexo entre o papel e as ações com ele relacionadas não surge de maneira espontânea, e cabe aos adultos descobri-lo para a criança". Ao brincarem com o tema hospital, as crianças criaram outras relações com a realidade, aliviando percepções desagradáveis em relação ao espaço real.

$\mathrm{O}$ indicador construções linguísticas inusitadas apresentou avanços quanto à linguagem, conduta, atenção, percepção, memória, um dos fatores de destaque foi uma situação da C. Manu, na qual ela comentou "não quero tirar sangue, tenho medo", a 
pesquisadora sugeriu que a criança ocupasse outro papel, e a criança escolheu ser médica ao invés de paciente.

O indicador alargamento dos horizontes cognitivos da criança mostrou que a criança faz uso de recursos sígnicos para ajudar a recordar, desse modo, a C. Jo Ar na prescrição da receita médica utiliza signos para registrar sua ideia: 1 Xa $2 x$ e 1 Com. $3 x$, cujo sentido atribuído pela criança era um xarope duas vezes e um comprimido três vezes. Outro elemento destacado neste indicador foi o uso do eixo da matriz curricular nomeado como tratamento de informação para informar quantos pacientes foram atendidos no hospital, pelo qual a criança pintava com cores uma tabela em forma de gráfico com diferentes figuras, como sutura, triagem, laboratório de raio x, atendidos pelo Samu, cirurgia, internação, consulta médica e sala de espera. Isso, além de oferecer conhecimentos matemáticos, proporcionou também a apropriação e o enriquecimento da linguagem em suas formas verbais e visuais.

\section{Conclusão}

$\mathrm{O}$ estudo apresentado indica que as crianças evoluíram psiquicamente durante a brincadeira, o que foi observado pelos instrumentos de análise, a partir das intervenções propostas pela professora e pesquisadora. Ao investigar a influência dos espaços organizados e a inserção de novos temas nas brincadeiras de papéis sociais, percebeu-se que ao preparar as crianças para a ação, colocando-as na categoria de atividade e buscando um planejamento intencional, proporcionou melhor atuação e representação dos papéis.

As três situações: $1^{a}$ Ação - Salão de Beleza; $2^{a}$ Ação - Clínica Veterinária e Pet Shop e $3^{\mathrm{a}}$ Ação - Hospital permitiram que as crianças se apropriassem de papéis que desconheciam e assim ao internalizá-los, objetivaram as falas e condutas assumidas durante a brincadeira.

Os indicadores analisados trouxeram à tona questões afetas ao desenvolvimento infantil, ficando explícito o desenvolvimento psíquico acerca da linguagem, conduta, pensamento, memória e atenção.

Finaliza-se, dando destaque às situações das brincadeiras de papéis sociais na Educação Infantil, salientando que essa atividade dominante na idade pesquisada proporciona saltos qualitativos no psiquismo humano.

\section{REFERÊNCIAS}


ARAÚJO, V. C. A brincadeira na instituição de Educação Infantil em tempo integral. O que dizem as crianças? $138 \mathrm{f}$. Dissertação (mestrado em Educação) - Universidade Federal de Juiz de Fora (UFJF), 2008.

ELKONIN, D. B. Psicologia do jogo. São Paulo: Martins Fontes. 2009.

LEONTIEV, A. N. Os princípios psicológicos da brincadeira pré-escolar. In: VIGOTSKI, Lev S.; LURIA, Alexander R.; LEONTIEV, Alexis N. Linguagem, desenvolvimento e aprendizagem. São Paulo: Ícone, 2006. p. 119 - 142.

GOBBO, G. R. R. O desenvolvimento da imaginação infantil mediado por gêneros discursivos e objetivado em desenhos e brincadeiras de papéis sociais. 291f. Tese (Doutorado em Educação) - Universidade Estadual Paulista (Unesp-Marília). Faculdade de Filosofia e Ciências, 2018.

MARCOLINO, S. A mediação pedagógica na Educação Infantil para o desenvolvimento da brincadeira de papéis sociais. 2013. 185 f. Tese (Doutorado em Educação). Faculdade de Filosofia e Ciências. Universidade Estadual Paulista, 2013.

ROSSLER, J. H. O papel da brincadeira de papéis sociais no desenvolvimento do psiquismo humano. In: ARCE, Alessandra; DUARTE, Newton (Org). Brincadeira de papéis sociais na educação infantil: as contribuições de Vigotski, Leontiev e Elkonin. São Paulo: Xamã, 2006. p. 51-63.

VIGOTSKI, L. S. A brincadeira e o seu papel no desenvolvimento psíquico da criança. In. VIGOTSKI, L. S. A. Revista virtual de gestão de iniciativas sociais. 2008, p. 23-36.

\section{Como referenciar este artigo}

GOBBO, Gislaine Rossler Rodrigues.; FERREIRA, Lucinéia Aparecida Alves. A brincadeira de papéis na educação infantil: atividade objetivada a partir da organização de espaços e da inserção de novos temas. Temas em Educ. e Saúde, Araraquara, v. 14, n. 2, p. 268-283, jul./dez., 2018. e-ISSN 2526-3471. DOI: 10.26673/tes.v14i2.12031

Submetido em: 05/10/2018

Revisões requeridas: $23 / 11 / 2018$

Aprovado em: 28/11/2018 